Svensk Teologisk Kvartalskrift 97 (202I), I33-I54

p-ISSN 0039-676I e-ISSN 2003-6248

DOI: https://doi.org/I0.51619/stk.v97i2.23193

\title{
Gudar och människor bland texter och paratexter
}

\author{
Om varför Gamla testamentet inte har några författare
}

DAVID DAVAGE

David Davage är docent i Gamla testamentets exegetik vid Lunds universitet och lektor i bibelvetenskap vid Høyskolen for ledelse og teologi i Oslo och Akademi för ledarskap och teologi i Umeå.

david.davage@altutbildning.se

"Död åt författaren!" Skulle huvudbudskapet i Roland Barthes (19151980) betydelsefulla och kärnfullt formulerade artikel "The Death of the Author" sammanfattas i ett slagord kan ett sådant imperativ tänkas ligga nära till hands. ${ }^{\mathrm{B}}$ Barthes, den franske litteraturkritikern som verkade under I900-talet, skrev förutom "The Death of the Author", som först kom ut 1967 på engelska, ${ }^{2}$ och sedan året därefter på franska, ${ }^{3}$ en rad texter som vidareutvecklade hans litteraturkritik i relation till samtida filosofiska strömningar,

Denna artikel är en varsamt bearbetad version av den docentföreläsning jag höll vid teologiska fakulteten, Lunds universitet den 22 september 2020. Jag har valt att behålla framställningens muntliga karaktär och hoppas att läsbarheten ändå ska vara god. Till sitt innehåll är artikeln också en sammanfattning av en längre argumentation som utgör den teoretiska bakgrunden till ett forskningsprojekt vid Umeå universitet där jag studerar utvecklingen av en jesajansk diskurs under andra templets tid (David Davage, How Isaiah Became an Author, under utgivning). Jag vill särskilt tacka professorerna Samuel Byrskog och Fredrik Lindström för hedrande inledande anföranden i samband med min föreläsning samt redaktionen på Svensk Teologisk Kvartalskrift för inbjudan till publicering. För den som vill höra föreläsningen i sin helhet finns den publicerad i podden Religion och Teologi den 24 september 2020, https://religionochteologi.podbean.com/e/david-davage-gudar-manniskorbland-texter-paratexter/, besökt 202I-05-03.

I. I denna artikel kommer citaten från Roland Barthes, "The Death of the Author", i Stephen Heath (red.), Image - Music - Text, London 1977, I42-I48.

2. Roland Barthes, "The Death of the Author", Aspen 5-6 (1967), https://www.ubu.com/ aspen/aspensand6/threeEssays.html\#barthes, besökt 202I-05-I2.

3. Roland Barthes, "La mort de l'auteur", Manteia 5 (I968), I2-I7. 
och vid sin tragiska död I980 hade han etablerat sig som en tongivande och internationellt ansedd forskare.

Som en inledning till denna artikel, där jag vill fundera över författarens funktion i relation till Gamla testamentets texter, är den kortfattade och något generiska presentationen av Barthes tänkt att illustrera en tydlig spänning i vår samtids sätt att förhålla sig till författare. Å ena sidan kan vi hålla med Barthes om att en författare inte enkelt kan nås genom studiet av dennes verk. Inte heller är biografiska levnadsskildringar tillräckliga för att komma åt författares intentioner, och visst är det så att en text alltid är summan av flertalet influenser som kan härledas till en mångfald av kulturer, genrer och tankeströmningar. Ingen text, eller författare, kan hävda originalitet i någon absolut mening. Att Barthes därför vill lossa texter ur deras författares grepp, eller närmare bestämt göra sig av med författaren i textstudiet, verkar rimligt. Romantikens idealbild - det kreativa geniet - är en chimär.

Samtidigt visar min inledning att Barthes nog inte lyckades ändå. För visst är det så att när vi läser Barthes texter är det just hans idéer vi försöker förstå, och till vår hjälp tar vi därför andra texter han författat, placerar honom i ett historiskt sammanhang och relaterar honom till dominerande vetenskapliga paradigm - strukturalism, poststrukturalism, romantikens författarideal eller marxism, för att nämna några. Kort sagt placerar vi författaren och hans intentioner $\mathrm{i}$ centrum för vårt studium av Barthes teorier om författarens död, det vill säga precis det som Barthes polemiserar emot:

To give a text an Author is to impose a limit on that text, to furnish it with a final signified, to close the writing. Such a conception suits criticism very well, the latter then allotting itself the important task of discovering the Author [...] beneath the work: when the Author has been found, the text is "explained" - victory to the critic. Hence there is no surprise in the fact that, historically, the reign of the Author has also been that of the Critic, nor again in the fact that criticism (be it new) is today undermined along with the Author. ${ }^{4}$

$\mathrm{Nu}$ skulle man kunna invända med att det egentligen inte är människan Barthes som är viktig för vårt resonemang. Vi försöker inte tränga in $\mathrm{i}$ Barthes inre för att nå ett kreativt genis intentioner. Namnet Barthes fyller i stället ett slags "författarfunktion" som avgränsar en specifik diskurs och hjälper klassificeringen av texter. Ett sådant resonemang, som kan härledas till Michel Foucault (1926-1984), ger viktiga pusselbitar till ett svar på

4. Barthes, "The Death of the Author", I47. Mina kursiveringar. 
frågan om varför författarens livskraft tycks ha varit stark nog att bestå Barthes attack. 5 Så som den förstås av Foucault liknar författarfunktionen nämligen den för tolkningen tvingande närvaro som Barthes vill göra sig av med. Författaren begränsar tolkningsalternativen. Vi skulle därför kunna tala om en tämjande funktion, eller med Gérard Genettes (1930-2018) begreppsapparat: en paratext. ${ }^{6}$ Som paratext skapar författarhänvisningen koherens. Den håller samman texten så att motsägelser tonas ned, ger den legitimitet och auktoritet, samtidigt som den för den samman med andra texter. Författardiskurserna är vidare inte statiska, konstanta eller universella, utan kan förändras över tid. Det innebär alltså att vår förståelse av Barthes, Foucault eller Genette alltid potentiellt kan ställas helt på ända om nya texter upptäcks som står i kontrast till etablerade tolkningar:

The "author-function" is tied to the legal and institutional systems that circumscribe, determine, and articulate the realm of discourses; it does not operate in a uniform manner in all discourses, at all times, and in any given culture; it is not defined by the spontaneous attribution of a text to its creator, but through a series of precise and complex procedures; it does not refer, purely and simply, to an actual individual insofar as it simultaneously gives rise to a variety of egos and to a series of subjective positions that individuals of any class may come to occupy.7

Foucault flyttar alltså i flera avseenden fram Barthes positioner. Samtidigt måste vi konstatera att de "tröttsamma upprepningar" ${ }^{3}$ som också Foucault vill komma ifrån - frågor som "who is the real author?", "have we proof of his authenticity and originality?" eller "what has he revealed of his most profound self in his language?" - ändå lever kvar, både i populärkulturen, litteraturvetenskapen och exegetiken, även om många kritiker i dag också ställer mer diskursorienterade frågor: "What are the modes of existence of this discourse?", "where does it come from; how is it circulated; who controls it?", "what placements are determined for possible subjects?" eller "who can fulfill these diverse functions of the subject?".

Som antytts ovan identifierar ett vanligt forskningshistoriskt narrativ ofta ursprunget till den seglivade fascinationen över författaren och dess betydelse för texten med romantikens idéer om det kreativa geniet. När Johann

5. Michel Foucault, "What Is an Author?", i Theresa Enos \& Stuart C. Brown (red.), Professing the New Rhetorics: A Sourcebook, Englewood Cliffs, NJ 1969, 178-193.

6. För en introduktion, se Gérard Genette, Paratexts: Thresholds of Interpretation, Cambridge 1997, https://doi.org/IO.IOI7/CBO9780511549373.

7. Foucault, "What Is an Author?", 309. Mina kursiveringar.

8. Foucault, "What Is an Author?", 3I4. 
Wolfgang von Goethe (I749-I832) skriver att författarskap innebär "the reproduction of the world around me by means of the internal world which takes hold of, combines, creates anew, kneads everything and puts it down again in its own form, manner", 9 sammanfattar han på ett koncist sätt ett slags ideal om en kreativ process som växer fram under romantiken där en tydligt värdeladdad dikotomi mellan originalitet och imitation är ständigt återkommande. Edward Young (I683-1765) uttrycker det enligt följande:

Originals are, and ought to be, great favorites, for they are great benefactors; they extend the republic of letters; And at a new province to its dominion: imitators only give us a sort of duplicates of what we had, possibly much better, before; increasing the mere drug of books, while all that makes them valuable, knowledge and genius, are at a stand. The pen of an original writer [...] out of a barren waste calls a blooming spring: out of that blooming spring an imitator is a transplanter of laurels, which sometimes die on removal, always languish in a foreign soil. ${ }^{\text {10 }}$

Bakom denna idé om kreativa genier och originalitet ligger naturligtvis en komplicerad process där författarskap förhandlats över tid. I sammanhanget har copyrightlagar såsom "Statute of Anne", som gav författare en förnybar fjortonårig rätt till sina verk, ${ }^{\text {II }}$ samt samtida debatter om piratkopiering som följde sannolikt haft avgörande betydelse. ${ }^{12}$ Samtidigt måste vi akta oss för att beteckna en specifik tidsperiod som unik. Faktum är att det finns tydliga kontinuiteter som riskerar att marginaliseras med en sådan ingång, och jag kommer i denna artikel försöka visa att det romantiska idealet har tydliga rötter i grekisk poetik, och då särskilt i den utveckling som författarbegreppet kom att genomgå under hellenistisk tid.

Det är också här som kopplingen till Gamla testamentets exegetik kommer att bli uppenbar. För visst är det så att en omistlig kärna i det exegetiska arbetet sedan disciplinens födelse har varit att kulturellt, historiskt och geografiskt kontextualisera en text för att på så sätt begränsa antalet möjliga tolkningar? För att komma så nära som möjligt en ursprunglig text och

9. Översatt i Martha Woodmansee, "The Genius and the Copyright: Economic and Legal Conditions of the Emergence of the 'Author", Eighteenth-Century Studies 17 (1984), 447.

Io. Edward Young, Conjectures on Original Composition in a Letter to the Author of Sir Charles Grandison, London I975, 339.

II. Se till exempel Betty A. Schellenberg, "The Eighteenth Century: Print,

Professionalization, and Defining the Author", i Ingo Berensmeyer, Gert Buelens \& Barysa Demoor (red.), The Cambridge Handbook of Literary Authorship, Cambridge 2019, 133-146, https://doi.org/I0.1017/9781316717516.009.

I2. För det senare, se till exempel Woodmansee, "The Genius and the Copyright". 
avtäcka dess betydelse? Och visst är det väl så att även om den tidiga historisk-kritiska forskningen gjorde upp med de författare som identifierats av traditionen - Mose för Moseböckerna, Jesaja för Jesajaboken, David för Psaltaren och Salomo för Predikaren, för att ta några exempel - blev inte steget vidare längre än att de i stället kom att ersättas av flera, anonyma författare eller tradenter (jämför tyskans Trägerkreise)? Befriade från traditionens tolkning av många av Gamla testamentets böckers inledande paratexter som författarangivelser förblev texterna anonyma. På goda grunder sågs de bibliska förgrundsfigurerna inte längre som de kreativa genier som gett upphov till innehållet i böckerna. Mycket - om inte det mesta - visade sig i stället vara skrivet långt senare, men kritikernas metoder gjorde att behovet av identifierbara upphovsmän bestod. I boken Ecclesiastes and the Riddle of Authorship formulerar Thomas M. Bolin paradoxen så här i relation till Predikaren och Salomo:

Once the author is no longer understood to be Solomon, the text becomes a series of clues, or enigmas, whose decipherment is supposed to reveal the author's time and identity. [...] Scholars now rely on linguistic, literary, and historical information to try and place the author of Ecclesiastes instead of traditions and texts connected with an assumed author. But the contexts derived from this historical data are just as much constructed as the biography of Solomon that readers built out of ancient textual traditions. It is also, like the constructed Solomonic biography, used to interpret the text. ${ }^{\mathrm{I}}$

Hur ska vi då förstå de paratexter som verkar identifiera en viss bibelbok med en person? Hur ska vi förstå de texter som talar om nedskrivande? Om inte paratexterna är författarangivelser, vad är de då? Och varför har i sådana fall Gamla testamentet inte några författare? För att svara på dessa frågor vill jag nu ge en översikt över vad jag menar är två tongivande och i många avseenden kontrasterande författarbegrepp som format både tillkomst och tolkning av Gamla testamentets texter och paratexter: ett grekiskt, som i vissa, men långt ifrån alla delar överlappar med romantikens ideal, och ett mesopotamiskt, som har vissa likheter med Barthes och Foucault, även om det också här finns avgörande skillnader.

En sådan ingång bör då genast kvalificeras: den är av nödvändighet heuristisk och vi ska inte förledas till att relatera endast ett författarbegrepp till en viss tid, någonting som vår egen tid med all önskvärd tydlighet påminner oss om. För är det inte så att det $\mathrm{i}$ vår tid finns ett starkt intresse

I3. Thomas M. Bolin, Ecclesiastes and the Riddle of Authorship, New York 20I7, 36. 
för författares livshistoria och de kreativa processer som gett upphov till välkända romaner samtidigt som författarbegreppet omförhandlas, både i relation till poststrukturalister som Barthes och Foucault, och i relation till det som ibland går under namnet Web 2.o, där vi ser en ökning av anonyma, samförfattade texter som till exempel Wikipediaartiklar, där det i stället för "writer" och "reader" eller "producer" och "consumer" blivit aktuellt att tala om "wreader" och "prosumer" (möjliga svenska motsvarigheter som "skräsare" och "pronsument" låter inte riktigt lika bra)? ${ }^{14}$

\section{Mesopotamien}

Vi beger oss först till Mesopotamien. I sin artikel noterar Foucault att man utan svårighet borde kunna föreställa sig en kultur där en diskurs cirkulerar utan någon författare, ${ }^{15}$ och här, i det antika Mesopotamien, är detta ett slående faktum. Under tusentals år cirkulerade texter helt utan författarangivelser. I biblioteks- och skolkataloger från Ur III, gammalbabylonisk och nyassyrisk tid listas till exempel en rad litterära verk. Referenspunkten är uteslutande incipiter, det vill säga de första orden i kompositionen, och sorteringen är inte sällan genrebaserad. ${ }^{16}$ Någonting som skulle kunna liknas vid "författare" lyser helt med sin frånvaro. Betyder detta att de inte hade något författarkoncept? Inte nödvändigtvis. Snarare är det så att ett sådant koncept sannolikt skiljer sig från de modeller vi noterat hittills. För att komma åt detta ska vi titta på hur de själva formulerar sig.

\section{När vävaren dör}

Vi börjar i en antologi med tempelhymner som efter den 42:a och sista hymnen har en intressant kolofon: "The compiler of the tablet (is) Enheduanna. My lord, that which has been created (here) no one has created (before)." ${ }^{17}$

Omnämnandet av Enheduanna har lett till att hon har omtalats som världshistoriens första författare, ${ }^{18}$ vilket naturligtvis har föranlett en mängd

I4. Se till exempel Adriaan van der Weel, "Literary Authorship in the Digital Age", i Ingo Berensmeyer, Gert Buelens \& Barysa Demoor (red.), The Cambridge Handbook of Literary Authorship, Cambridge 2019, 218-234, https://doi.org/I0.1017/9781316717516.0I4.

I5. Foucault, "What Is an Author?", 3I4.

I6. För en samlad översikt och diskussion av dessa kataloger, se David Willgren, The Formation of the "Book" of Psalms: Reconsidering the Transmission and Canonization of Psalmody in Light of Material Culture and the Poetics of Anthologies, Tübingen 2016, 395-403.

17. Åke W. Sjöberg \& Eugen Bergmann (red.), The Collection of the Sumerian Temple Hymns, Locust Valley, NY 1969, 49. Kolofoner, det vill säga skrivarnotiser angående en lertavla eller skriftrulles innehåll, är väl studerade och en god översikt finns i Hermann Hunger, Babylonische und Assyrische Kolophone, Neukirchen-Vluyn 1968.

I8. Se till exempel William W. Hallo, Origins: The Ancient Near Eastern Background of Some Modern Western Institutions, Leiden 1996, 266; William W. Hallo \& Johannes J.A. Van Dijk, Exaltation of Inanna, New Haven, CT 1968. Jämför Sophus Helle, ”Enheduanna and the 
frågor. Vem var hon? När levde hon? Har hon verkligen författat dessa hymner? Man har till exempel noterat att några hymner verkar komma från en tid senare än Enheduannas. ${ }^{19}$ Hur ska vi då tänka? Det första vi får observera är att det bakom ordet som översatts med "compiler" gömmer sig en viktig metafor. Ordet skulle nämligen hellre kunna översättas med "vävare". ${ }^{20}$ Den som vävt denna samling är Enheduanna. Samtidigt sägs det att det som skapats är helt nytt. Blir inte detta en självmotsägelse? Nyckeln ligger i metaforen: en väv vävs alltid av redan existerande trådar, och denna handling kan samtidigt resultera i mönster som inte förut existerat. Här implicerar alltså den sumeriska kolofonen en författarförståelse som överlappar med Barthes resonemang på en viktig punkt: innehållet i tempelhymnssamlingen har inte uppstått "ur intet". Väven är ur det avseendet inte ett kreativt genis innovation. Romantikens dikotomi mellan originalitet och imitation faller samman. Samtidigt ska också noteras att även om Enheduanna förekommer här, är hon inte omnämnd i katalogerna som listar tempelhymnerna. I en katalog från Nippur från cirka 2000 f.v.t. är antologin i stället upptecknad

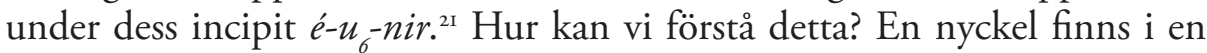
annan av de texter som förknippats med henne, dikten The Exaltation of Inanna. Här besjungs nämligen textens tillkomst:

"This filled me, this overflowed from me, Exalted Lady, as I gave birth for you. What I confided to you in the dark of night, a singer shall perform for you in the bright of day! Because of your assaulted wife, because of your assaulted child, Great was your fury, remorseless your heart." The almighty queen, who presides over the priestly congregation, She accepted her prayer. $^{22}$

Texten är fascinerande, inte minst utifrån födelsemetaforen. Tidigare i dikten har det berättats om en stad vars sköte är ur funktion och det beskrivs hur kvinnorna på natten inte längre söker råd eller avslöjar sina hjärtans rena tankar för sina makar. Likheterna med den avslutande skildringen är

Invention of Authorship", Authorship 8 (2019), I-20, https://doi.org/IO.21825/aj.v8ir.II486.

19. Se Willgren, The Formation of the "Book" of Psalms, 47.

20. För liknande observationer, se också Sophus Helle, "What Is an Author? Old Answers to a New Question", Modern Language Quarterly 80 (2019), I23-I28, https://doi. org/IO.I2I5/00267929-7368183, som också ger en kort historisk översikt över metaforen, som naturligtvis också finns inbakad i ordet "text" (lat. textus = "väv[nad]").

2I. Se Samuel N. Kramer, "The Oldest Literary Catalogue: A Sumerian List of Literary Compositions Compiled about 2000 B.C.", Bulletin of the American Schools of Oriental Research 88 (1942), I6 med n. 2I, https://doi.org/I0.2307/I355474.

22. Översättning från Benjamin R. Foster, The Age of Agade: Inventing Empire in Ancient Mesopotamia, London 2016, 335 . 
slående. Resultatet av Enheduanna och Inannas framgångsrika dialog nattetid - en dialog med möjliga sexuella undertoner - är en metaforisk födelse: dikten. I sin studie av mesopotamiskt författarskap pekar assyriologen Sophus Helle också på en konsekvens av detta: födelsen innebär att barnet separeras från sin moder. ${ }^{23}$ I detta fall syns detta både genom att dikten framförs av en sångare och i det att dikten byter från första till tredje person. Enheduanna - som i dikten vänt sig till Inanna efter att ha blivit förvisad från sin prästtjänst av en man vid namn Lugalanne - upprättas, men försvinner samtidigt ut ur bilden. Författarskap innebär i denna text alltså inte att Enheduanna sätts i främsta rummet, vare sig som kreativ upphovskvinna (jämför romantiken) eller författarfunktionell diskursmarkör (jämför Foucault). I stället förstås författarskap som en samverkan mellan flera aktörer:

In order for authors to become authors, they must recruit a community of performers, copyists, and readers who are willing to continue the circulation of the text and thereby carry it beyond its original context. This kind of cooperation both constitutes the authors, as it allows their text to circulate as a work of literature, and removes the authors from their own work, as the text is handed over to others. [...] After the lines "what I have told you in the dead of night, / a gala shall repeat for you at midday," the gala becomes the new speaker of the text, and so the "I" disappears. ${ }^{24}$

Efter Enheduanna följer århundraden av tystnad, men att denna författarförståelse inte ska ses som världshistoriskt unik kan anas om vi förflyttar oss framåt i tiden, till en period då personer mer systematiskt börjar förknippas med texter, nämligen den nyassyriska tiden där inte minst Assurbanipals omfattande samlande av litteratur till sina bibliotek kom att markera något av en milstolpe i mesopotamisk litteraturhistoria. ${ }^{25}$ Här återfinns bland annat en katalog i tre kopior som av Wilfred G. Lambert (I926-20II) fått namnet "A Catalogue of Texts and Authors". ${ }^{26}$ Men att dessa "författare" inte kan anses motsvara vare sig romantikens författarideal eller Foucaults författarfunktion blir snart tydligt. Katalogen omnämner nämligen inte

23. Sophus Helle, "The Birth of the Author", Orbis Litterarum 75 (2020), 64, https://doi. org/IO.IIII/oli.I2250.

24. Helle, "The Birth of the Author", 65 .

25. För en översikt, se till exempel Jeanette C. Fincke, "The Babylonian Texts of Nineveh: Report on the British Museum's Ashurbanipal Library Project", Archiv für Orientforschung 50 (2003), III-I49.

26. Wilfred G. Lambert, "A Catalogue of Texts and Authors", Journal of Cuneiform Studies I6 (1962), 59-77, https://doi.org/I0.2307/1359154. 
bara människor, utan också gudar och legendariska kungar som personer som "talat" texter. På ett ställe är "författaren" till och med en häst(!). Listan är ändå viktig, eftersom den tillsammans med andra texter målar en bild av en mesopotamisk förståelse av författare. Tre exempel kan få illustrera detta.

\section{Sammanflätad agens}

Det första exemplet är att katalogen nämner Erraeposets incipit, "[King of All Habitations, Creator of] the World Region", följt av "[This is what] was revealed to [Kabti-ilāni-Marduk, son of Dābibi], and which he spoke". ${ }^{27}$ Här talas alltså om en uppenbarelse, och intressant är att Erraeposet självt avslutas med en liknande formulering: "The compiler of his tablets was Kabti-ilāni-Marduk, son of Dābibu: he (guden Ishum[?]) revealed it to him in a nocturnal vision and, just as he (Kabti-ilāni-Marduk[?]) declaimed it while wakeful so he left nothing out, he added to it not a single line." ${ }^{28}$

Visionen har tydliga likheter med avslutningen av The Exaltation of Inanna. Även här leder en interaktion mellan en gudom och en mänsklig mottagare till en text. Att notera i sammanhanget är att talarna är diffusa - "he revealed it to him [...] just as he [...] he added" - vilket gör texten svåröversatt. ${ }^{29}$ Forskare har länge försökt reda ut texten utan att någon koncensus har uppnåtts. Men kanske är just otydligheten en viktig pusselbit? I stället för att som Lambert tala om att vi här har en "tacit admission that the wording did not originate with him", ${ }^{30}$ kan vi notera en sammanflätning av gudomlig och mänsklig agens som resulterar i att den "ursprungliga" mänskliga mottagaren till slut försvinner ut ur bilden. Texten fortsätter nämligen med att guden Erra hör och bekräftar texten, och så förkunnas det att sångare som sjunger detta inte ska dö av pest, att skrivare inte ska falla för fiendehand och att hus i vilka lertavlorna med eposet på förvaras kommer att få gudomligt beskydd. Även här betyder ordet som översatts "compiler" vävare, så att dikotomin mellan originalitet och imitation fortsatt suddas ut. Kabti-ilāni-Marduk fyller alltså snarast en funktion som kanal, som

27. Lambert, "A Catalogue of Texts and Authors", 65.

28. Översättning från Andrew R. George, ”The Poem of Erra and Ishum: A Babylonian Poet's View of War", i Hugh Kennedy (red.), Warfare and Poetry in the Middle East, London 2013, 60-6I, https://doi.org/10.5040/9780755607969.ch-002. Se också Benjamin R. Foster, "Authorship in Cuneiform Literature", i Ingo Berensmeyer, Gert Buelens \& Barysa Demoor (red.), The Cambridge Handbook of Literary Authorship, Cambridge 2019, I4-I5, https://doi. org/I0.1017/9781316717516.002.

29. Notera till exempel att Benjamin R. Foster ändrat sig över tid. Från att ha tänkt att det är Ishum som uppenbarar något för Kabti-ilāni-Marduk (Benjamin R. Foster, Before the Muses: An Anthology of Akkadian Literature, vol. 2, 2:a uppl., Bethesda, MD I996, 910) argumenterar han 2019 för det omvända scenariot (Foster, "Authorship in Cuneiform Literature", 19-20).

30. Wilfred G. Lambert, "Ancestors, Authors, and Canonicity", Journal of Cuneiform Studies II (I957), I, https://doi.org/I0.2307/1359284. 
första mottagare och traderare, i likhet med Enheduanna, och precis som Enheduanna kommer han att marginaliseras i den fortsatta traderingen.

\section{Förkroppsligad interaktion}

Ett andra intressant exempel utgörs av den ovan nämnda katalogens hänvisning till Gilgamesheposet tillsammans med en viss Sîn-lēqi-unninni. Det är väl känt att Gilgamesheposet både var mycket populärt över en väldigt lång tid och att det samtidigt genomgick ett antal större förändringar. ${ }^{3 \mathrm{I}}$ Från att under det tredje årtusendet före vår tideräknings början ha bestått av enskilda berättelser om Gilgamesh på sumeriska, till att under det andra årtusendet ha funnits i ett antal sammansatta versioner, kom den att under det första årtusendet etableras till en standardversion på akkadiska som bland annat återfanns i Assurbanipals bibliotek. Medan de tidigare stadierna var anonyma förknippas alltså nu standardversionen med en möjlig "författare": Sîn-lēqi-unninni. Bara observationen att namnet förknippas med en version som bygger på en lång tradering illustrerar på ett bra sätt den vävmetafor som använts explicit i tidigare exempel, men ytterligare en observation kan göras i relation till författarförståelse. Under den nyassyriska tiden - då vi alltså har ett antal skildringar av hur gudars och människors interaktion resulterar i texter - får Gilgamesheposet en ny prolog, och intressant nog innehåller den en skildring av nedtecknande som i Jeffrey $\mathrm{H}$. Tigays översättning lyder:

[Him who] saw everything, let me [make kno]wn to the land, | [Who all thing]s experienced, [let me tea]ch i[t] ful[ly]. [...] [The hi]dden he saw, the undisclosed he discov[ered]. He brought back information from before the flood, | Achieved a long [j] ourney, exhausted, but at peace. | All his toils he [engra]ved on a (stone) stela / an inscription. ${ }^{32}$

Gilgamesh, som förkroppsligar den tidigare interaktionen mellan gud och människa genom att själv vara halvgud, beskrivs här som förmedlare av förflodsvisdom och som nedtecknare. Vi skulle alltså kunna tolka detta i linje med texttillkomstnarrativen ovan. Ändå är det inte Gilgamesh som listas i katalogen, utan Sîn-lèqi-unninni. Den distributiva, mottagarorienterade författardefinitionen lyser igenom med full kraft.

3I. För en ingående diskussion, se Jeffrey H. Tigay, The Evolution of the Gilgamesh Epic, Philadelphia, PA 1982.

32. Tigay, The Evolution of the Gilgamesh Epic, 153 . 


\section{Den förste av många}

Ett tredje och sista exempel hämtar vi från Enuma elish. Här beskrivs nämligen den första mottagaren på ett för vår diskussion klargörande sätt som just "den förste":

They (the fifty names of Marduk) must be grasped: let the "first one" explain (them). Let the wise and knowledgeable discuss (them) together. Let the master repeat (them) to make the pupil understand. [...] The explanation (of the names) which the "first one" discoursed before him (Marduk). He wrote down and preserved for those in the future to hear. ${ }^{33}$

Diktens ursprung förläggs inte hos en enskild "författare", i stället används beteckningen "den förste", vilket indikerar att den alltså var tänkt att följas av fler. Helle formulerar det så här: "but the first link in that chain was not particularly important; what mattered was only that it was kept going." ${ }^{34}$ Texten uppmanar de visa och insiktsfulla att diskutera Marduks namn, och faktum är att det är precis så vi också senare ser att texten tolkas. I den nyassyriska tiden växer nämligen också en ny genre fram - kommentarlitteraturen. ${ }^{35}$ Här förklaras svårigheter i texter (ofta lingvistiska), men till skillnad från hur kommentarlitteratur ofta ser ut i dag har den första mottagaren ingen betydelse för tolkningen. Det kan hänvisas till andra källor, men då genom deras incipiter. Två exempel kan ges. Det första är från en kommentar till just Marduks namn, där vi ser en vanligt återkommande uppställning där ord förklaras genom att synonymer listas i parallella kolumner:

\begin{tabular}{|c|c|c|}
\hline dingir & i-lum & dingir (the divine determinative) (means) "god" \\
\hline tuIM & $\check{s} a ́-a-r i$ & $\mathrm{tu}_{[\mathrm{Is}]}[\mathrm{IM}]$ (means) "breeze" \\
\hline duㅡㅍ & $t a-a-b u$ & $\mathrm{du}_{[\mathrm{ro}]}^{[1] \mathrm{HI}]}$ (means) "fair" \\
\hline dingir & be-lum & dingir (means) "lord" \\
\hline $\mathrm{zi}$ & $\check{s} e-m u-u ́$ & zi (means) "to hear" \\
\hline & $m a-g a-r u m$ & zi (means) "to accede" ${ }^{36}$ \\
\hline
\end{tabular}

33. Översättning från Benjamin R. Foster, "On Authorship in Akkadian Literature", Annali dell'Università degli Studi di Napoli "L'Orientale" 5I (199I), 2I-22. 46.

34. Sophus Helle, The First Authors: Narratives of Authorship in Ancient Iraq, Århus 2020,

35. En introduktion och översikt finns i Eckart Frahm, Babylonian and Assyrian Text Commentaries: Origins of Interpretation, Münster 20II. Totalt har nära 900 lertavlor från 700-talet till roo-talet f.v.t. hittats i utgrävningar och långt ifrån alla är ännu översatta.

36. Frahm, Babylonian and Assyrian Text Commentaries, II5. 
En annan kommentar, på Enuma elish, liknar mer det vi känner igen från Qumran som peshertexter. ${ }^{37}$ Här citeras bastexten, följt av en utläggning: "'The gods shall bring in their presents before him' (Enuma Elish VII IIo), (This refers to) the presents that are given in the month of Nisannu from the sixth day to the twelfth day; (it is) because of Zababa, as it is said." 38

Även om vissa texter kopplas ihop med namn läses de alltså inte i ljuset av dem. I stället förstås de i relation till den ovan beskrivna traderingsorienterade mottagaridén. Det blir också uppenbart när vi gör observationen att när de personer som anges i "författar"-katalogen också omtalas i andra sammanhang nämns inte "deras" texter. Vi kan föreställa oss hur Barthes ler i sin grav vid tanken på så döda författare; där de personer som omnämns varken ses som källor för inspiration eller tradition och där de mänskliga mottagarna och traditionsförmedlarna närmast kan förstås som vävare som väver traditionens trådar till ständigt nya former. Ytterst blir alltså resultatet att den första "vävaren" decentraliseras, även när hon nämns vid namn.

\section{Jesaja}

Om vi med detta i åtanke vänder oss mot Gamla testamentet är min tes att det vi ser i mycket liknar den mesopotamiska författarförståelsen. Precis som i Mesopotamien är texterna till övervägande del anonyma och de enstaka fall där texter inleds med paratexter som omnämner personer - detta gäller framför allt profetlitteraturen - kan utan problem förstås i linje med den bild som tecknats här. För att ge ett tydligt exempel på detta vänder jag mig nu därför till just profetlitteraturen, mer specifikt till en bok vars "författarskap" varit omdiskuterat sedan bibelvetenskapens födelse - ofta på romantikens premisser. ${ }^{39} \mathrm{Jag}$ talar om Jesaja bok. Här hittar vi nämligen en inledande paratext (Jes. I:I), som under många århundraden har tolkats som en författarangivelse. Liknande formuleringar upprepas sedan i Jes. 2:I och I3:I: ${ }^{40}$

- Jesaja ben Amos syner, som han såg (I:I)

- Ordet som Jesaja ben Amos såg angående Juda och Jerusalem (2:I)

- Babelprofetian (bördan) som Jesaja ben Amos såg (I3:I)

37. För en jämförelse mellan mesopotamiska kommentarer och pesherlitteraturen, se Bronson Brown-deVost, Commentary and Authority in Mesopotamia and Qumran, Göttingen 2019 .

38. Frahm, Babylonian and Assyrian Text Commentaries, II3.

39. För en uppdaterad forskningsöversikt, se Ulrich Berges, "Isaiah: Structure, Themes, and Contested Issues", i Carolyn J. Sharp (red.), The Oxford Handbook of the Prophets, Oxford 2016, I53-170, https://doi.org/IO.IO93/oxfordhb/9780199859559.013.9.

40. Om inget annat anges är översättningarna mina egna. 
De tre paratexterna liknar varandra syntaktiskt genom att de innehåller formuleringen asher chazah - "som han såg". Det som förmedlas är alltså att det i texten som följer kommer att berättas någonting som en profet skådat. Precis som i den mesopotamiska traditionen målas alltså bilden av profeten som mottagare. Orden är, så att säga, inte profetens egna. Han är i stället indragen $\mathrm{i}$ en process där ord visas för honom. Ser vi på andra profetböckers paratextuella inramning är bilden densamma:

- Herrens ord som var till Hosea, Beris son. [...] Början av Herrens ord genom Hosea (Hos. I:I-2)

- Herrens ord som var till Joel, Petuels son (Joel I:I)

- Herrens ord som var till Mika från Moreset [...] som han såg (Mik. I:I)

- Herrens ord som var till Sefanja, Kushis son (Sef. I:I)

- Herrens ord var till Sakarja, Berekjas son (Sak. I:I)

Sammanflätningen av mänsklig och gudomlig agens är uppenbar. Betoningen ligger på att Herrens ord uppenbaras till eller genom profeten, som har sett det. Samma sak skulle vi se om vi citerar Hesekiel, Jeremia, Amos, Obadja eller Habbakuk. Vi kan också observera att formuleringarna antyder att även om profeter nämns i paratexterna är det inte profeternas röst som hörs där. Precis som i avslutningen av The Exaltation of Inanna har ytterligare röster vävts in, så att de ord som profeterna fått se nu förmedlas vidare av andra. Författarskap fördelas alltså på fler aktörer och i Jesaja beskrivs detta explicit på ett antal ställen. Vi tittar först på Jes. 8:I6: ”Bind ihop vittnesbördet (teudah)! Försegla undervisningen (torah) i mina lärjungar!"

Likt Erraeposets ambivalenta formuleringar är det här oklart vem som ger uppmaningen..$^{41}$ Är det Gud eller "Jesaja"? ${ }^{22}$ Den närmsta kontexten antyder att det skulle vara den senare, vilket innebär att vi i så fall får en inblick i hur de visioner som Jesaja sett ska leva vidare. ${ }^{43}$ Men vi kan också se det som en indikation på att rösterna inte kan (eller bör?) skiljas åt. Notera dock att vittnesbördet (teudah) och undervisningen (torah) inte beskrivs som talarens

4I. Hebreiskan är otydlig (ska verben till exempel förstås som imperativ, i linje med den masoretiska vokaliseringen, eller som infinitiv absolut?) och dess lydelse har diskuterats ingående i kommentarlitteraturen. Eftersom de olika alternativen inte påverkar det övergripande resonemanget här hänvisar jag i stället läsaren till Hugh G.M. Williamson, The Book Called Isaiah: Deutero-Isaiah's Role in Composition and Redaction, Oxford 1994, 97-103, https://doi.org/I0.I093/or98263600.00I.00oI.

42. Notera dock att ingen profet nämns vid namn. Den vanliga identifikationen med Jesaja bygger i stället på de ovan citerade paratexterna - paratexter som sannolikt lagts till i ett senare skede.

43. En god översikt finns i John D.W. Watts, Isaiah I-33, Grand Rapids, MI 2004, I59-I60. 
- här har Bibel 2000 en olycklig översättning: ”Jag vill knyta in min undervisning, jag vill gömma mitt budskap under sigill i mina lärjungar". Däremot beskrivs lärjungarna tillhöra talaren. Den undervisning som profeten först mottagit skulle alltså nu föras vidare av andra än honom själv; lärjungarna blir de som har tillgång till den medan profeten "väntar" på Herren (Jes. 8:17). ${ }^{44}$ Anmärkningsvärt är att ingenting sägs om själva innehållet. ${ }^{45}$ Det är helt enkelt inte poängen. Vad texten i stället beskriver är att någons lärjungar nu är auktoriserade traderare av de uppenbarelser som mottagits av en (anonym) "första" mottagare och att deras förvaltande har som syfte att visa för senare generationer att dessa uppenbarelser var sanna. En sådan tolkning gör också de annars enigmatiska verser som följer begripliga. ${ }^{46} \mathrm{Här}$ återkommer nämligen vittnesbördet och undervisningen i ett ironiskt fördömande av folket som rådgör med de döda å de levandes vägnar. Poängen verkar vara att eftersom undervisningen finns tillgänglig hos den första mottagarens lärjungar kan folket få del av detta även när "den förste" själv är död. Det finns ingen anledning att som Saul väcka upp en gammal profet (I Sam. 28:7-25). Sådant beteende fördöms. Texten vittnar därmed om en decentralisering av den första mottagaren till förmån för kommande generationers förmedling av undervisningen, någonting som också syns tydligt $\mathrm{i}$ Jes. 30:8-9, där nedskrivande nämns:

Gå och skriv ner det på en tavla inför dem, pränta det i en bokrulle, så att det bevaras för kommande dagar som ett vittnesbörd för all framtid.

Ty detta är ett motsträvigt folk, barn som är trolösa, som vägrar att lyda vad Herren befallt" (ordagrant "Herrens undervisning", torah) ${ }^{47}$

"Jesaja" (återigen är texten dock anonym) uppmanas här skriva ner någonting på en tavla (luach) eller bokrulle (sefer) och texten skulle därför kunna

44. Texten har varit en central del i tesen om en så kallad "Jesajaskola”. Se till exempel Douglas Jones, "The Traditio of the Oracles of Isaiah of Jerusalem", Zeitschrift für die alttestamentliche Wissenschaft 67 (1955), 226-224. Men texten förstås alltså bättre i ljuset av mesopotamisk författarförståelse.

45. Detta har inte hindrat forskare från att tolka metaforen bokstavligt och spekulera om vad i Jesaja "bok" som kan ha varit avsett med en sådan formulering, se till exempel diskussionen i Williamson, The Book Called Isaiah, 97-I03.

46. För en diskussion av dessa verser, se till exempel Joseph Blenkinsopp, Isaiah I-39, New York 2000, 244.

47. Översättningen är hämtad från Bibel 2000. 
tolkas som ett slags mise en abyme, en "spegeltext" som ger en inblick i Jesaja boks tillkomst. Jag tror att det ligger något i det, men kanske inte på det sätt som det ofta tolkats. Det är nämligen vanligt att forskare försöker identifiera vad i Jesaja bok som denna tavla kan ha innehållit, för att på så sätt möjligen kunna spåra stoff tillbaka till en historisk person som levde på 700-talet (eller 6oo- eller 50o-talet) f.v.t. - en profets ipsissima verba.$^{48}$ En sådan läsning, som utgår från romantikens författarideal, missar dock någonting avgörande. Två observationer kan förtydliga detta. För det första står luach parallellt med sefer, med luach först. ${ }^{49}$ Det indikerar att det här egentligen inte rör sig om någon omfattande bokrulle, utan om en mer begränsad text, så att sefer hellre skulle översättas med "blad". Det andra är att texten säger att någonting ska skrivas ner "inför dem", vilket liknar symbolhandlingen i Jes. 8:I, där profeten skriver "Maher shalal hash bas" på en stor tavla inför två vittnen. ${ }^{50}$ Sammantaget skulle detta alltså tyda på att det som skrivs här helt enkelt är det som sagts i versen innan: "Rahab, som är stilla." "ri Vi kan också notera att det som i kapitel 8 omtalades som "undervisning" här tydligt kopplas till JHWH genom konstruktionen "Herrens undervisning". Syftet med nedtecknandet blir också återigen framåtriktat: kommande generationer ska kunna se att det som sagts varit sant. Att en profet här uppmanas att skriva vittnar alltså om de processer som identifierats i det mesopotamiska materialet och kan svårligen tjäna som underlag för att identifiera olika agenter i bokens tillkomsthistoria.

Vilka slutsatser kan då dras angående konstruktionen av författarskap i Jesaja bok? Traditionellt har man tänkt sig att det bakom "Jesaja" döljer sig en mängd personer som varit med och skrivit boken, så att det bara är när man ryckt loss etiketten som man med textens hjälp kan komma åt författarna (ofta beskrivna som "tradenter", jämför Bolin ovan). Läst i ljuset av mesopotamisk författarförståelse ser vi i stället något annat. Sättet som boken relateras till Jesaja liknar i mycket det sätt som Enheduanna, Kabti-ilāniMarduk med flera relateras till texter. Författarskap konceptualiseras som en interaktion mellan flera agenter. Vi kan alltså hellre säga att det framför

48. Se till exempel Hans Wildberger, Isaiah 28-39, Minneapolis, MN 2002, I39-I43; John N. Oswalt, The Book of Isaiah: Chapters I-39, Grand Rapids, MI 1986, 550-55I.

49. Parallellismen ska inte tolkas som att det rör sig om två separata dokument, som är fallet i till exempel Gary V. Smith, Isaiah I-39, Nashville, TN 2007, 515.

50. Brevard S. Childs, Isaiah, Louisville, KY 200I, 226, menar att den närmsta parallellen inte är 8:I, utan 8:I6, det vill säga texten som analyserades ovan. Mitt argument ovan är inte i någon egentlig polemik mot ett sådant synsätt, eftersom det inte finns något skäl att spela ut den ena texten mot den andra. Nedskrivandet i 8:16 tjänar samma syfte som det i Jes. 30, medan den performativa handlingen i sig liknar den i 8:I.

5I. Så också till exempel John H. Hayes \& Stuart A. Irvine, Isaiah: The Eight Century Prophet, Nashville, TN $1987,340$. 
"Jesaja" finns en stadig ström av legitimerade tradenter med ansvar för att gräva nya kanaler för det vatten som flödar genom den första mottagaren. Jesaja boks tre inledande paratexter kan tillsammans med beskrivningarna av texttradering därför med fördel förstås i ljuset av vävmetaforen: det som påbörjats genom "Jesaja" och förts vidare av flera generationer lärjungar blir över tid ett vackert stycke som vävs av traditionens trådar på ett sådant sätt att den första vävaren decentraliseras. Jesaja må ha blivit viktig som diskursmarkör à la Foucault, men den bild som tecknas här är långt ifrån romantikens idé om författares kreativa geni med betoning på författarintention och originalitet.

Jesajas decentralisering skymtar också fram tydligt i kommentarlitteraturen från andra templets tid - de sex peshertexterna på Jesaja bok..$^{52} \mathrm{Om}$ nämnandet av Jesaja fyller i dessa texter inte någon annan funktion än den som referensmarkör. Själva kommentarerna är ointresserade av både Jesajas tid och någon författares eventuella intentioner. Det som tolkas är i stället uppenbarelsen. Det syns också i en annan fascinerande text från Qumran - 4QI76 (4QTanḥumim) - som väver samman citat ur Jesaja bok med nykomponerat material, så att nya röster fogas till den första mottagarens syner. ${ }^{53}$

Det skulle nu kunna påpekas att jag i denna artikel bara har talat om profeter och att relationen mellan gudomligt och mänskligt här får en specifik karaktär. Som svar kan då påpekas att det i huvudsak är just dessa profetböcker som försetts med namn. Övriga böcker är generellt sett utan sådana paratexter. Dessutom är det just profeter som omnämns som författare när Första och Andra Krönikeboken berättar om hur Israels historia traderats. ${ }^{54}$ Man skulle också kunna påpeka att profeters nedtecknande görs mer explicit $\mathrm{i}$ andra profetböcker, inte minst $\mathrm{i}$ Jeremia, men utan att här kunna lägga ut texten vågar jag påstå att en mesopotamisk författarförståelse fungerar väl som förklaringsmodell även här. Samtidigt står det klart att ju längre fram i tiden vi kommer, desto mer verkar det mesopotamiska vävas samman med någonting annat, med en kontrasterande författarförståelse som också kommer att påverka hur man under slutet av andra templets tid kom att tolka

52. För en översikt, se till exempel George J. Brooke, "Isaiah in the Pesharim and Other Qumran Texts", i Craig C. Broyles \& Craig A. Evans (red.), Writing and Reading the Scroll of Isaiah: Studies of an Interpretive Tradition, vol. 2, Leiden 1997, 609-632, https://doi.

org/Io.II63/9789004275959_oio; George J. Brooke, "On Isaiah at Qumran", i Claire Mathews McCinnis \& Patricia K. Tull (red.), "As Those Who Are Taught": The Interpretation of Isaiah from the LXX to the SBL, Leiden 2006, 69-85.

53. Se till exempel Jesper Høgenhaven, "The Literary Character of 4QTanhumim”, Dead Sea Discoveries I4 (2007), 99-I23, https://doi.org/IO.II63/I56851707779141173.

54. Se särskilt William M. Schniedewind, The Word of God in Transition: From Prophet to Exegete in the Second Temple Period, Sheffield 1995. 
paratexter som den i Jes. I:I. Det har därför blivit dags att titta på den andra stora traditionen jag nämnde i inledningen: den grekiska.

\section{Grekland}

Vända västerut möts vi nämligen av en kultursfär där texter inte längre är anonyma och där författaren inte bara är en marginaliserad del i en längre traderingskedja. I den nyutkomna Cambridge Handbook of Literary Authorship tecknar Ruth Scodel fem karaktärsdrag för arkaisk och klassisk grekisk författarsyn: (I) författare ses som källor för inspiration och auktoritet, (2) det finns ett starkt fokus på författarintention, (3) författare ses som ansvariga för det som deras verk innehåller, (4) det finns en tävlingsaspekt bland författare som skapar ett behov av att skilja ut sig samt att (5) författare blev viktiga bärare av kulturell identitet. ${ }^{55}$

Till skillnad från de mesopotamiska katalogerna och kommentarerna som listade incipiter, hänvisar man ofta i den grekiska kontexten till böcker genom personer och när man tolkar dessa texter blir en förståelse för deras intention viktig. I Aristoteles $\mathrm{Om}$ diktkonsten lyser detta igenom tydligt: författare beskrivs som avgörande i utformandet av litterära verk och att poeterna skulle vara kreativa källor med ansvar för sina verk är ständigt förutsatt. De kan hyllas eller anklagas för saker som karaktärer i deras verk säger eller gör, och att författare anses påstå saker i sina verk gör att även hänvisningar till anonyma verk sker via författaren. Så här skriver till exempel Aristoteles om relationen mellan Homeros och en anonym poet:

As regards narrative mimesis in verse, it is clear that plots, as in tragedy, should be constructed dramatically, that is, around a single, whole, and complete action, with beginning, middle, and end, so that epic, like a single and whole animal, may produce the pleasure proper to it. [...] That is why, as I said earlier, Homer's inspired superiority over the rest can be seen here too [...] but the others build their works round a single figure or single period, hence an action of many parts, as with the author of the Cypria and the Little Iliad. ${ }^{6}$

För författare blev det därför viktigt att också markera vems texten var. Se till exempel Theognis:

55. Ruth Scodel, "Authorship in Archaic and Classical Greece", i Ingo Berensmeyer, Gert Buelens \& Barysa Demoor (red.), The Cambridge Handbook of Literary Authorship, Cambridge 2019, 46-63, https://doi.org/I0.I0I7/9781316717516.004.

56. Stephen Halliwell et al. (red.), Aristotle, Poetics; Longinus, On the Sublime; Demetrius, On Style, Cambridge, MA I995, II5-II7. 
Cyrnus, as I perform my skill let a seal [sphragis] lie upon these words, and they will never be stolen unnoticed, nor will anyone trade something worse for the good that is available; and everyone will say: "These are the verses of Theognis, the Megarian, known by name throughout all humanity." ${ }^{7}$

En idé om intellektuell egendom och jakten på författarens intention kan alltså inte sägas vara en romantikens ex nihilo-skapelse. Dryga två tusen år tidigare skriver Platon i Protagoras att:

The opening of the ode [of Simonides] must at once appear crazy if, while intending to say that it is hard for a man to become good, he inserted "indeed." There is no sort of sense, I imagine, in this insertion, unless we suppose that Simonides is addressing himself to the saying of Pittacus as a disputant: Pittacus says - It is hard to be good; and the poet controverts this by observing - No, but to become good, indeed, is hard for a man, Pittacus, truly - not truly good; he does not mention truth in this connection, or imply that some things are truly good, while others are good but not truly so: this would seem silly and unlike Simonides..$^{58}$

Även om romantikens författarideal naturligtvis inte kan likställas med det grekiska ser vi alltså tydliga överlappningar, och det gäller också intresset för författarnas liv: i antikens Grekland intar författaren en centralposition. Implicita biografiska narrativ extraheras från verken och relateras till övrig känd information för att skapa spännande biografiska skildringar som sedan i sin tur används för att tolka verken. Författare blir statyer. ${ }^{59}$

Denna typ av författarförståelse får också en rad konsekvenser. När homeriska epos eller andra texter tydligt kopplas till specifika personer, och när sådana personer blir avgörande för tolkningen av texter, kommer anonyma texter $\mathrm{i}$ allt högre utsträckning att behöva tillskrivas författare. Samtidigt kommer andra texter, i ljuset av kunskap om författares liv och verk, att anses vara felaktigt tillskrivna, och eftersom stora summor betalas ut för klassiska verk uppstår frestelsen att förfalska:

57. Citatet är från Scodel, "Authorship in Archaic and Classical Greece", 55. Intressant i sammanhanget är att även om denna passage ger uttryck för en stark betoning på författarens egendom har forskare argumenterat för att några av dikterna i samlingen inte alls kommer från Theognis. Se Hendrik Selle, Theognis und die Theognidea, Berlin 2008, https://doi. org/IO.I515/9783110209648.

58. Walter R.M. Lamb (red.), Plato: Laches, Protagoras, Meno, Euthydemus, Cambridge, MA 1924, 199. Mina kursiveringar.

59. Jämför Barbara Graziosi, Inventing Homer: The Early Reception of Epic, Cambridge 2002. 
If at any place I will insert the name of Aesopus, to whom I already paid the debt that I owed, let it be known that I do so for the sake of authority, as some artists do in our age who fetch a greater price for their newly made artifacts if they ascribe the name of Praxiteles to their statue, that of Mys to smooth silver, that of Zeuxis to a painting. To such an extent biting envy is more favorable to adulterated ancientness than to the good works of the present (Faidros, 5 Praef.). ${ }^{60}$

Förfalskning som terminologi blir alltså bara relevant i en grekisk kontext, inte i en mesopotamisk, och i den förra kommer också det som forskare kallat för Echtheitskritik att utvecklas. ${ }^{61}$ I samband med byggandet av bibliotek i Alexandria och Pergamon där rullar bland annat skulle ordnas efter författare tog nämligen äkthetsdiskussioner fart. Korrekta författarangivelser blev också någonting viktigt i samband med utgivning av texter och de alexandrinska grammatikerna kom därför att ta fram ett system med kritiska tecken som placerades i marginalen för att visa vad en skrivare ansåg om en viss vers äkthet. ${ }^{62}$ Att detta kom att utvecklas i en grekisk kontext ska dock inte primärt ses som ett resultat av bibliotekens behov. Vi såg ovan hur Assurbanipals projekt inte ledde till några äkthetsdiskussioner. I stället får det härledas till att det i grunden föreligger olika författarbegrepp.

Vad innebar då denna äkthetskritik? Kort sagt kan sägas att de hellenistiska grammatikerna ställde upp olika kriterier för att avgöra om en text hade rätt tillskrivning. Man tittade i huvudsak på stil, vokabulär, sakinnehåll, eventuella motsägelser samt anakronismer. Redan Herodotos hade ifrågasatt om Homeros hade skrivit Cypria eftersom författaren inte verkade känna till geografin på samma sätt som Homeros, och att äkthetskritiken kom att få stort inflytande kan ses i till exempel Dionysius från Halikarnassos texter, där han ifrågasätter att vissa texter kopplats ihop med Dinarkos: ”There still remains one very necessary task, to determine his [Dinarkos'] life-span in order to be able to say something definite on the matter of which speeches are genuinely his and which are not" (De Din. II). ${ }^{63}$

6o. Ur Irene Peirano, The Rhetoric of the Roman Fake: Latin Pseudepigrapha in Context, Cambridge 20I2, 51, https://doi.org/IO.IOI7/CBO9780511732331. Min kursivering.

6I. För en beskrivning, se till exempel Wolfgang Speyer, Die Literarische Fälschung im Heidnischen und Christlichen Altertum: Ein Versuch Ihrer Deutung, München 1971; Peirano, The Rhetoric of the Roman Fake.

62. Speyer, Die Literarische Fälschung, II6; Peirano, The Rhetoric of the Roman Fake, 39.

63. Översättning hämtad från Hindy Najman \& Irene Peirano Garrison, "Pseudepigraphy as an Interpretative Construct", i Matthias Henze \& Liv Ingeborg Lied (red.), The Old Testament Pseudepigrapha: Fifty Years of the Pseudepigrapha Section at the SBL, Atlanta, GA 2019, 337, https://doi.org/IO.2307/j.ctvr33b6k.20. 
Dionysius går vidare och konstaterar genom denna undersökning att det finns verk som skulle ha skrivits innan Dinarkos författarskap tog sin början och därför måste anses vara felaktigt tillskrivna honom - pseudepigraphoi logoi eisin oide. Det är alltså i denna kontext som pseudepigrafi uppstår; i de hellenistiska grammatikernas jakt på feltillskrivna texter, och detta påverkar naturligtvis också författarnas egna reflektioner:

I know, dear Bassus, the reason why many publish my work as their own: for it was given to friends and students without ascription (epigraphe) , because they were not intended for publication, but in response to those who asked to have my lecture notes on what they heard. (Galenos, De libris propriis) ${ }^{64}$

Som ett sista exempel på författarens centralitet i en grekisk kontext får Kallimachos bibliografiska verk Pinakes tjäna. Tyvärr kan det bara rekonstrueras genom några få fragment och senare referenser, men det sägs ha omfattat I2O rullar och utgjorde en förteckning av böcker i biblioteket i Alexandria. ${ }^{65}$ Det intressanta i jämförelse med det mesopotamiska materialet är att Kallimachos inte bara listar titlar och författare, utan att han också gör biografiska noteringar samt diskuterar datering och autenticitet, något som senare hänvisningar till Pinakes gör tydligt:

He [Parmenides] philosophizes in verse, just as Hesiod, Zenophanes and Empedokles [...] and it seems that he was the first to discover that the Evening star and the Morning star are the same; but others say it was Pythagoras. Kallimachos, however, says that the work was not by him [i.e. not by Pythagoras]. ${ }^{66}$

Sammantaget kan vi se att det pågår ett intensivt samtal om författarskap i hellenistisk tid och givet den grekiska kulturens snabba spridning är det inte förvånande att vi också ser att denna författarsyn sakta kommer att vävas samman med den mesopotamiska och därför påverka tolkningen av Gamla testamentets paratexter.

\section{Hur Gamla testamentet fick författare}

Spår av grekisk influens på mesopotamisk litteratur syns tydligt i en av de sista bevarade katalogerna, en katalog från Uruk från tvåhundratalet före

64. Peirano, The Rhetoric of the Roman Fake, 46. Min kursivering.

65. Se Rudolf Blum, Kallimachos: The Alexandrian Library and the Origins of Bibliography, Madison, WI I99I.

66. Citerat från Blum, Kallimachos, 158. Min kursivering. 
vår tideräknings början - strax före kilskriftskulturens utdöende. Här listas kungar tillsammans med skrivare i ett försök att visa på den mesopotamiska litteraturhistoriens storhet, ${ }^{67}$ och särskilt intressant är att Sîn-lēqi-unninni och Kabti-ilāni-Marduk nämns på ett sätt som förflyttar Sîn-lēqi-unninni ända tillbaka till Gilgamesh tid: "[I]n the time of king Gilgamesh: the scholar was Sin-leqi-unninni. [In the time of] king [Nara]m-Sîn (?): the scholar was Kabti-ili-Marduk." ${ }^{8}$

Från att ha varit ett anonymt epos har Gilgamesh alltså först kommit att kopplas ihop med en skrivare i nyassyrisk tid, Sîn-lēqi-unninni, men i ljuset av en grekisk författarförståelse har denna tillskrivning nu kommit att tolkas som att skrivaren måste ha levt på Gilgamesh tid.

En liknande utveckling ser vi också vad gäller Gamla testamentet. Ett exempel får illustrera detta, nämligen Josefus. När Josefus skriver Judarnas antikviteter blir det tydligt att han gör det med en grekisk författarförståelse och att detta präglar hans tolkning av texterna. Han omnämner till exempel Moses som författare till Pentateuken och han talar om Jesaja som tydligt kopplad till nedskrivandet av hela Jesaja bok. Han är inte längre en första mottagare av en gudomlig uppenbarelse som sedan kanaliseras till efterkommande generationer att förvalta:

As for the prophet, he was acknowledged to be a man of God and marvellously possessed of truth, and, as he was confident of never having spoken what was false, he wrote down in books all that he had prophesied and left them to be recognized as true from the event by men of future ages. $\left(\right.$ Ant. 10.35) ${ }^{69}$

Att allt kommer från Jesaja blir också tydligt när Josefus talar om den persiske kungen Kyros den store:

These things Cyrus knew from reading the book of prophecy which Isaiah had left behind two hundred and ten years earlier. For this prophet had said that God told him in secret, "It is my will that Cyrus, whom I shall have appointed king of many great nations, shall send my people to their own land and build my temple." Isaiah prophesied these things one hundred and forty years before the temple was demolished. $(\text { Ant. II. } 5-7)^{70}$

67. Se Helle, The First Authors, 238-254.

68. Citerat från Helle, The First Authors, 360.

69. Citerat från Ralph Marcus (red.), Josephus: Jewish Antiquities, Volume 4, Books 9-II, Cambridge, MA 1937, I77. Min kursivering.

70. Citerat från Marcus, Josephus, 315-317. Mina kursiveringar. 
Så har alltså den döda författaren till slut vaknat till liv och intagit den centrala position i både texttradering och texttolkning som Barthes knappa två tusen år senare menade att den inte skulle ha. Trädets rötter nådde djupare än Barthes kanske anat. Därför räckte det inte med ett yxhugg för att det skulle dö. Paradoxalt nog satte Barthes i sitt försök att bli av med författaren ändå sitt eget namn i centrum och författaren levde vidare. Kanske är det så att det är upptäckten av ett helt annat rotsystem som låter oss få syn på vår egen förståelsehorisont. Kanske är det först då vi också kan decentralisera spekulationer kring antalet kreativa genier och deras historiska sammanhang och i högre utsträckning tala om Gamla testamentets texter och deras tillkomst med historiskt relevanta författarteorier. Kanske får vi då syn på väven av trådar där det gamla och det nya möts i ständigt nya konfigurationer och där agenter som vi annars vill hålla isär knyts ihop på sätt som gör dem omöjliga att skilja åt. För vad skiljer egentligen en författare från en redaktör, en skrivare från en författare eller en profet från sina lärjungar? Gamla testamentets texter kom att färdigställas i skärningspunkten mellan grekisk äkthetskritik och mesopotamisk traditionsförmedling. Ytterst innebär det att vi behöver fortsätta att reflektera över några av de mest fundamentala aspekterna av Gamla testamentets exegetik: relationen mellan en bok och dess författare.

\section{SUMMARY}

It is a well-known fact that the books of the Hebrew Bible are, to a great extent, anonymous and that the individuals long identified as their authors (Moses, Isaiah, David, Solomon, and so on) are not the ones who have penned them. How, then, should the few paratexts that do, in fact, relate texts explicitly to named individuals be understood? In this article, I argue that such a question is essentially related to the historical contingency of author concepts. After introducing the work of Roland Barthes and Michel Foucault as a contrast to the Romantic author ideal, I provide an outline of two diverging author concepts in the ancient world: (1) a Mesopotamian trajectory where texts often circulated anonymously and where authorship was distributed across several agents, with a divinehuman interaction at its core, and (2) a Greek trajectory, where authors were regularly named and given prime place in the interpretive activity. By arguing that there are clear overlaps in the way authorship is conceived in the Mesopotamian trajectory and in the Hebrew Bible (more specifically in the book of Isaiah), I provide a new framework in relation to which the formation of the literature of the Hebrew Bible can be understood. 